Check for updates

Institute of Infection, Veterinary and Ecological Sciences, University of Liverpool, Liverpool, UK

2 The COVID-19 Genomics UK (COG-UK) Consortium, University of Cambridge, Cambridge, UK

3 A*STAR Infectious Diseases Laboratories, Agency for Science, Technology and Research, Singapore

4 Health Protection Research Unit in Emerging and Zoonotic Infections, Liverpool, UK

Correspondence to: J A Hiscox Julian.Hiscox@liverpool.ac.uk Cite this as: BMJ 2021;372:n771 http://dx.doi.org/10.1136/bmi.n771 Published: 23 March 2021

\section{Covid-19: variants and vaccination}

\section{We have the tools to track variants and adapt vaccines as required}

\author{
Alistair C Darby, ${ }^{1,2}$ Julian A Hiscox 1, 3,4
}

SARS-CoV-2 has been in the human population for more than a year now, causing severe disease in some and resulting in a pandemic that continues to put severe strain on economies and healthcare infrastructures worldwide. ${ }^{1}$ In the UK, the first three vaccines have emergency use authorisation, and a national rollout is in progress. Many other countries are also instigating large scale vaccination programmes. These vaccines express the spike glycoprotein, the major target of neutralising antibodies in a natural infection. The vaccines protect against disease, ${ }^{2-4}$ and preliminary data suggest that transmission is also decreased after vaccination. ${ }^{5}$

Current vaccines are based on a version of the spike glycoprotein from the start of the outbreak, however, and central questions remain around the ability of an old version of the spike glycoprotein to generate protective antibodies against newer emerging variants. The linked paper by Challen and colleagues (doi:10.1136/bmj.n579) suggesting that variant of concern B.1.1.7 might be associated with increased mortality adds urgency to these questions. ${ }^{6}$

SARS-CoV-2 infections can be established by multiple virus genotypes within the same person, ${ }^{7}$ and together with new rounds of virus replication, provide the raw material for natural selection. The extent of genetic diversity in a viral population is critical to natural selection for growth advantages such as better binding to the receptor, faster replication, and more effective suppression or avoidance of the host immune response.

A popular misconception, currently receding, is that SARS-CoV-2 mutates more slowly than other viruses. Genome sequencing of SARS-CoV-2 shows a nucleotide substitution rate of roughly $1 \times 10^{-3}$

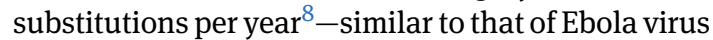
$\left(1.42 \times 10^{-3}\right) .9$ SARS-CoV-2 (and coronaviruses in general) throw up variants all the time, and they do this through single point mutations, recombination, insertions, and deletions. ${ }^{10}$ These changes can lead to altered pathogenesis, and tracking them is vital.

The value of real time viral genomic sequencing was a major lesson from the Ebola virus disease outbreak in west Africa. ${ }^{11}{ }^{12}$ Sequencing of SARS-CoV-2 occurs worldwide, but particularly in the UK, through the efforts of the COVID-19 Genomics UK (COG-UK) consortium. By conducting a continuous nationwide surveillance programme, almost in real time, the likely origin and spread of SARS-CoV-2 variants can be identified.

Considerable attention has been paid to changes in the spike glycoprotein and how these influence transmission dynamics and risk of immune escape. All the current variants of concern (lineages B.1.351,
B.1.1.7, and P1) have multiple differences from the original Wuhan variant that affect the function of the spike glycoprotein and other SARS-CoV-2 proteins. Mutations in the spike can alter interaction with receptor hACE2. ${ }^{13}$

For example, compared with the Wuhan reference sequence, all current variants of concern have the $\mathrm{N}_{501 Y}$ substitution, and all these lineages can carry the E484K substitution in the spike glycoprotein. Additionally, both B.1.351 (first identified in South Africa) and P1 lineages (first identified in Brazil) have a K417T substitution, whereas B.1.1.7 (first identified in Kent, UK) and $\mathrm{P} 1$ share the same 11288:9 deletion (source https://cov-lineages.org/). That these mutations seem to be associated with greater transmission suggests that spike variants should be monitored carefully as part of routine genomic surveillance, and also shows the need for studies to characterise the threat posed by potential mutations of concern.

Variants of concern might be associated with changes in both morbidity and mortality. Worse outcomes might be due to higher viral loads in infected individuals, altered transmission dynamics, or suppression of the host immune response. Some variants with deletions in viral genes that suppress the innate response are associated with milder infections, ${ }^{14}$ but Challen and colleagues report evidence that a B.1.1.7 variant might be associated with an increase in mortality. ${ }^{6}$ This is consistent with animal studies showing increased weight loss in Syrian hamsters infected with a B.1.1.7 lineage, compared with controls infected with a previously circulating strain. ${ }^{15}$

\section{Protecting the future}

Some countries will be slower than others to vaccinate their populations. SARS-CoV-2 and its variants will be around for some time, and concerns around the protection afforded by current vaccines will continue. The risk of immune escape is hard to predict long term, but we do know from experience with avian coronavirus that vaccines against one variant will protect against similar variants but not always against highly divergent variants.

Currently available vaccines will likely offer protection against prevailing variants of SARS-CoV-2. However, multivalent vaccines might be more robust in the longer term. Multivalent vaccines would probably include the viral nucleoprotein, which has less selection pressure than the spike glycoprotein, due to critical functions in binding the viral genome.

Vaccines against SARS-CoV-2 will be needed for many years, and those vaccines will change as variants become too divergent, similar to vaccines against 
influenza. National and global surveillance, together with well controlled assays to rapidly identify and characterise variants of concern, will allow us to move from current reactive approach to something much more proactive.

Competing interests:

The BMJ has judged that there are no disqualifying financial ties to commercial companies.

The authors declare the following other interests: none.

The BMJ policy on financial interests is here: https://www.bmj.com/sites/default/files/attachments/resources/2016/03/16-current-bmj-education-coi-form.pdf."

Provenance and peer review: Commissioned; not externally peer reviewed.

1 Dorward DA, Russell CD, Um IH, etal. Tissue-Specific Immunopathology in Fatal COVID-19. Am J Respir Crit Care Med 2021;203:192-201. doi: 10.1164/rccm.202008-32650C. pmid: 33217246

2 Voysey M, Clemens SAC, Madhi SA, etalOxford COVID Vaccine Trial Group. Safety and efficacy of the ChAdOx1 nCoV-19 vaccine (AZD1222) against SARS-CoV-2: an interim analysis of four randomised controlled trials in Brazil, South Africa, and the UK. Lancet 2021;397:99-111. doi: 10.1016/S0140-6736(20)32661-1. pmid: 33306989

3 Baden LR, El Sahly HM, Essink B, etalCOVE Study Group. Efficacy and Safety of the mRNA-1273 SARS-CoV-2 Vaccine. N Engl J Med 2021;384:403-16. doi: 10.1056/NEJMoa2035389. pmid: 33378609

4 Polack FP, Thomas SJ, Kitchin N, etalC4591001 Clinical Trial Group. Safety and Efficacy of the BNT162b2 mRNA Covid-19 Vaccine. N Engl J Med 2020;383:2603-15. doi: 10.1056/NEJMoa2034577. pmid: 33301246

5 Levine-Tiefenbrun M, Yelin I, Katz R, etal. Decreased SARS-CoV-2 viral load following vaccination.medRxiv 2021:2021.02.06.21251283. doi: 10.1101/2021.02.06.21251283

6 Challen R, Brooks-Pollock E, Read JM, Dyson L, Tsaneva-Atanasova K, Danon L. Risk of mortality in patients infected with SARS-CoV-2 variant of concern 202012/1: matched cohort study. BMJ 2021;372:n579. doi: 10.1136/bmj.n579 pmid: 33687922

7 Moore SC, Penrice-Randal R, Alruwaili M, etal. Amplicon-Based Detection and Sequencing of SARS-CoV-2 in Nasopharyngeal Swabs from Patients With COVID-19 and Identification of Deletions in the Viral Genome That Encode Proteins Involved in Interferon Antagonism. Viruses 2020;12:E1164. doi: 10.3390/v12101164. pmid: 33066701

8 Duchene S, Featherstone L, Haritopoulou-Sinanidou M, Rambaut A, Lemey P, Baele G. Temporal signal and the phylodynamic threshold of SARS-CoV-2. Virus Evol 2020;6:a061. doi: 10.1093/ve/veaa061. pmid: 33235813

9 Carroll MW, Matthews DA, Hiscox JA, etal. Temporal and spatial analysis of the 2014-2015 Ebola virus outbreak in West Africa. Nature 2015;524:97-101. doi: 10.1038/nature14594. pmid: 26083749

10 Davidson AD, Williamson MK, Lewis S, etal. Characterisation of the transcriptome and proteome of SARS-CoV-2 reveals a cell passage induced in-frame deletion of the furin-like cleavage site from the spike glycoprotein. Genome Med 2020;12:68. doi: 10.1186/s13073-020-00763-0. pmid: 32723359

11 Carroll MW. Retrospective versus real-time Ebola virus sequencing. Lancet Infect Dis 2019;19:567-8. doi: 10.1016/S1473-3099(19)30207-5. pmid: 31000466

12 Pini A, Zomahoun D, Duraffour S, etal. Field investigation with real-time virus genetic characterisation support of a cluster of Ebola virus disease cases in Dubréka, Guinea, April to June 2015. Euro Surveill 2018;23. doi: 10.2807/1560-7917.ES.2018.23.12.17-00140. pmid: 29589579

13 Yi C, Sun X, Ye J, etal. Key residues of the receptor binding motif in the spike protein of SARS-CoV-2 that interact with ACE2 and neutralizing antibodies. Cell Mol Immunol 2020;17:621-30. doi: 10.1038/s41423-020-0458-z. pmid: 32415260

14 Young BE, Fong SW, Chan YH, etal. Effects of a major deletion in the SARS-CoV-2 genome on the severity of infection and the inflammatory response: an observational cohort study. Lancet 2020;396:603-11. doi: 10.1016/S0140-6736(20)31757-8. pmid: 32822564

15 Clark JJ, Sharma P, Bentley EG, etal. Naturally-acquired immunity in Syrian Golden Hamsters provides protection from re-exposure to emerging heterosubtypic SARS-CoV-2 variants B.1.1.7 and B.1.351.bioRxiv 2021:2021.03.10.434447. doi: 10.1101/2021.03.10.434447

This article is made freely available for use in accordance with BMJ's website terms and conditions for the duration of the covid-19 pandemic or until otherwise determined by BMJ. You may use, download and print the article for any lawful, non-commercial purpose (including text and data mining) provided that all copyright notices and trade marks are retained. 